Hydrogen peroxide containing 10 percent by weight of water was obtained from the Buffalo Electrochemical Company. It was further purified and concentrated by vacuum distillation. Deuterium peroxide was prepared by the method of Feher, ${ }^{3}$ the amount of hydrogen present in the final sample being estimated at 8 to 10 percent of the deuterium content based on a comparison of band intensities. The spectra were obtained with a PerkinElmer Model 12B which had been modified into a double beam instrument recording directly the percent transmission; a fluorite, rock salt or potassium bromide prism was used depending on the region. The cell used has been described by Wagner and Hornig, ${ }^{4}$ the sample being contained in a small silver chloride holder which provided a fixed film thickness of about 15 microns. At the temperatures employed, decomposition during the course of two or three hours was small.

The bands observed for supercooled liquid hydrogen peroxide ( 99.2 percent) and liquid deuterium peroxide ( 82.5 percent) at $-30^{\circ} \mathrm{C}$ and for crystalline hydrogen peroxide at $-30^{\circ}$ and $-78^{\circ}$ are listed in Table I. The low frequency band noted by Giguère

TABLE I. Infra-red frequencies of hydrogen and deuterium peroxides.

\begin{tabular}{|c|c|c|c|c|c|}
\hline \multicolumn{2}{|c|}{$\mathrm{H}_{2} \mathrm{O}_{2}$} & \multicolumn{2}{|c|}{$\mathrm{D}_{2} \mathrm{O}_{2}$} & \multirow[b]{2}{*}{$\begin{array}{l}\text { Sym- } \\
\text { metry }\end{array}$} & \multirow[b]{2}{*}{$\begin{array}{c}\text { Assign- } \\
\text { ment }\end{array}$} \\
\hline $\begin{array}{l}\text { Liq.. } \\
-\mathbf{3 0}\end{array}$ & $\begin{array}{c}\text { Cryst., } \\
-30^{\circ}\end{array}$ & $\begin{array}{c}\text { Cryst., } \\
-78^{\circ}\end{array}$ & $\begin{array}{l}\mathrm{Liq} . . \\
-30^{\circ}\end{array}$ & & \\
\hline $635 m, b r$ & & $\begin{array}{l}472 v w \\
660 s \\
792 w\end{array}$ & $538 m, b r$ & & $\nu_{4}(?)$ \\
\hline $878 v w$ & & $878 w w$ & $878 w w$ & $a$ & $\nu ;$ \\
\hline \multirow[t]{2}{*}{$1353 m s$} & $1365 s$ & $1378 s$ & $\begin{array}{c}1004 s \\
(1386 w)\end{array}$ & $b$ & $\nu 6$ \\
\hline & $1418 w$ & $1430 w$ & & $a$ & $\nu_{2}$ \\
\hline $2796 \mathrm{mw}, \mathrm{br}$ & $2743 m$ & $2733 \mathrm{~m}$ & $2087 m w$ & & $\nu_{2}+\nu_{6}(?)$ \\
\hline $3360^{*} v s$ & $3275 * v s$ & 3218 vs & $\begin{array}{c}2482 \text { vs } \\
(3368 \mathrm{mw})\end{array}$ & $\stackrel{b}{b}$ & $\nu_{6}$ \\
\hline 4715 vw & $4640 v w$ & $4595 v w$ & & $A$ & $\nu_{6}+\nu_{6}$ \\
\hline
\end{tabular}

* Obtained by difference from the combination band, $\nu_{6}+6$.

was observed in the liquid at $-30^{\circ}$ as a broad band of moderate intensity with a maximum at $635 \mathrm{~cm}^{-1}$. In the deuterium sample under similar conditions, the maximum appeared at $538 \mathrm{~cm}^{-1}$. The observed ratio of hydrogen to deuterium frequency is thus 1.18 , whereas the Teller-Redlich product rule, using the known frequencies ${ }^{2}$ of the other vibrations of the same species, predicts a ratio of approximately 1.35 for $\nu_{4}$, the torsional motion of the $\mathrm{OH}$ groups. The spectrum of crystalline hydrogen peroxide at $-78^{\circ}$ exhibited considerably more detail than the liquid and is shown in Figs. $1 \mathrm{a}$ and $1 \mathrm{~b}$. Both the intensity and sharpness of the low frequency band increased markedly compared to the liquid and two new bands of low intensity appeared separated from the main maximum by $132 \mathrm{~cm}^{-1}$ and $188 \mathrm{~cm}^{-1}$ on the high and low frequency sides respectively. The $132 \mathrm{~cm}^{-1}$ frequency agrees well with the difference of $135 \mathrm{~cm}^{-1}$ found between the main Raman OH band in the crystal and a subsidiary band on its high frequency side ${ }^{2}$ and probably can be assigned to a lattice vibration. The spectrum of crystalline deuterium peroxide was not obtained and further experimental work will be necessary to establish conclusively the nature of the band at $660 \mathrm{~cm}^{-1}$ in the crystal spectrum.

The unsymmetrical bending mode, $\nu_{6}$, was also much sharper and more intense in the crystal at $-78^{\circ}$; the sharp and rather weak band on its high frequency side appears at the position expected for $\nu_{2}$, the symmetrical bending mode, which is also allowed in the infra-red but which until now has only been observed in the Raman spectrum. The shoulder on the low frequency side appears due to the first overtone of the $660 \mathrm{~cm}^{-1}$ band.

The band around $2800 \mathrm{~cm}^{-1}$, on the basis of the above data, cannot be given the assignment proposed by Giguère. The shape and position of the band at $2733 \mathrm{~cm}^{-1}$ in the crystal at $-78^{\circ}$
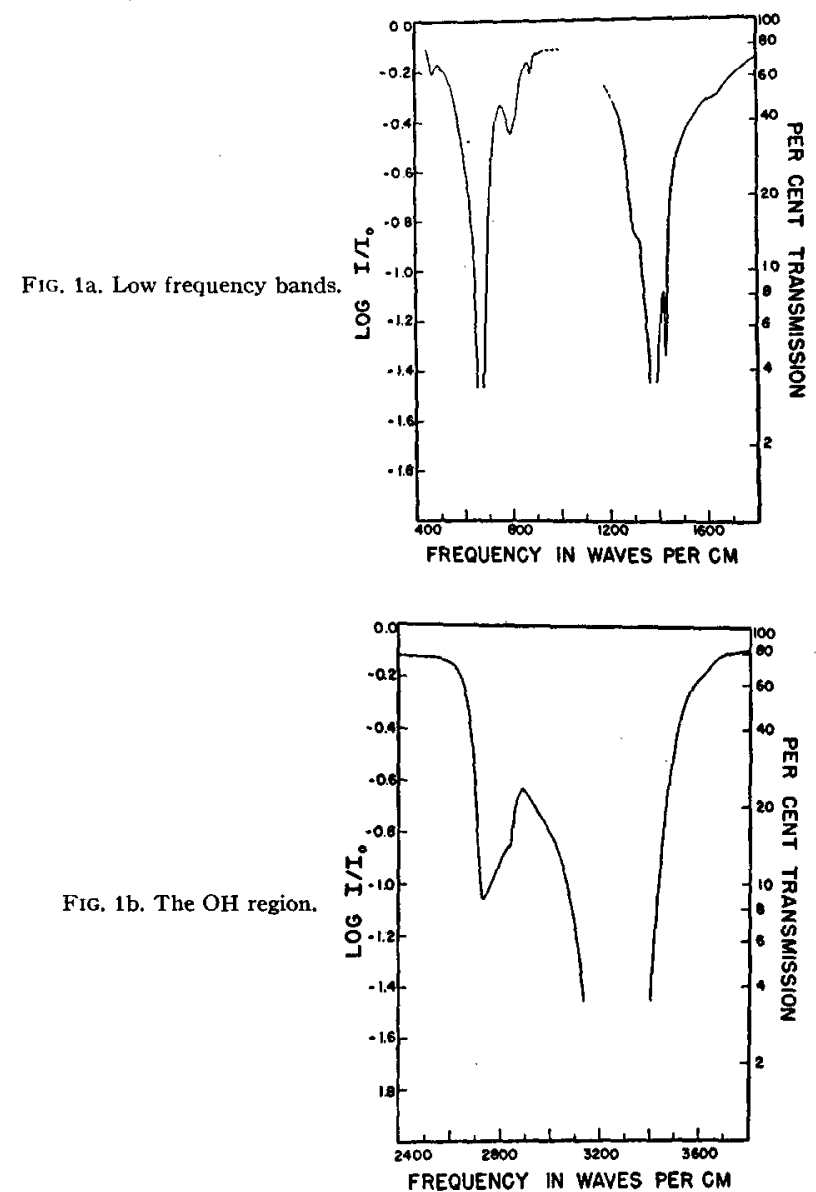

suggest that it is due to the unresolved overtones of the two bending modes, $\nu_{2}$ and $\nu_{6}$. However, both fundamentals shift to higher frequencies as the crystal temperature decreases, whereas the $2733 \mathrm{~cm}^{-1}$ band shifts slightly to lower. Further work over a wider range of temperatures seems necessary for a more satisfactory answer.

It is hoped that work can be resumed on this problem shortly and a more complete account presented in the fairly near future. The author would like to express his appreciation to Dr. Giguère for making his manuscript available in advance of publication.

* This work was supported by the ONR under Contract N6Ori-88, Task Order No. 1 .

** Present Address: Department of Chemistry, University of Michigan, Ann Arbor, Michigan.

$+\mathrm{Dr}$. Giguère, in a private communication, reports this band now at $610 \mathrm{~cm}^{-1}$ at room temperature.

1 P. A. Giguère. J. Chem. Phys. 18, 88 (1950).

2 R. C. Taylor, Thesis, Brown University, Providence, R. I. (1947)

${ }^{3}$ F. Feher, Ber. d. d. Chem. Ges. 72, 1789 (1939).
E. Wagner and D. F. Hornig, J. Chem. Phys, 18, 296 (1950).

\section{Remarks on Mizushima's Method for the Determination of Surface Area of Powders}

YiNG Fu

Department of Chemistry, University of Michigan, Ann Arbor, Michigan April 14, 1950

R ECENTLY Mizushima ${ }^{1}$ proposed a method for the deter1 mination of surface area of powders using adsorption and adhesion tension data. His method is based on the following 
equations :

$$
\begin{gathered}
k T \int_{1}^{n} \ln \frac{p_{s}}{p(\nu)} d \nu=a\left(\sigma_{s}-\sigma_{s l}\right), \\
a=\frac{k T \int_{1}^{n} \ln \left(p_{s} / p(\nu)\right) d \nu}{\sigma_{l v} \cos \theta}
\end{gathered}
$$

where $p_{s}$ is the saturation pressure of the liquid, $p(v)$ is the vapor pressure at which $\nu$ molecules of the vapor are adsorbed by a solid of area $a, \sigma_{s}, \sigma_{s l}$, and $\sigma_{l v}$ are respectively the interfacial tensions of the solid-vacuum, solid-liquid, and liquid-vapor interfaces and $\theta$ is the contact angle. It is believed the theory is fundamentally unsound and the alleged experimental support non-existent.

Equation (1) was obtained by equating the change of free energy, $\Delta G$, of the adsorbate to the change of the available surface energy of the adsorbent. Since these two effects are entirely different, it is not correct to equate the one to the other to obtain Eq. (1). This can be easily demonstrated when the equations for these energy changes are compared. For a single adsorbate at constant temperature,

$$
\Delta G=\int \mu d \nu
$$

where $\mu$ is the chemical potential; for the adsorbent,

$$
\sum_{\substack{\text { all surface } \\ \text { phases }}} \int a d \sigma=-\int \nu d \mu
$$

by the familiar Gibbs' equation. Obviously $\Delta G$ cannot be identified with $a\left(\sigma_{s}-\sigma_{s l}\right)$ as Mizushima has contended.

The transformation of Eq. (1) into (2) by means of du Pré's equation, $\sigma_{v l} \cos \theta=\sigma_{s}-\sigma_{s}$, involves another common misconception. The du Pré equation is strictly an equilibrium relation. If a liquid spontaneously spreads on a solid surface, equilibrium evidently does not exist, and the du Pré equation is no longer valid. In such cases it is not permissible to assume that the contact angle is zero, because spontaneous spreading indicates there is no contact angle which is quite different from a zero angle. The system toluene-glass used by Mizushima is precisely such a system to which the du Pré equation cannot be applied, because toluene will spontaneously spread on glass. Even granting that it is permissible to apply the du Pré equation to such systems, Mizushima's fourth equation

$$
\sigma_{l_{v}} \cos \theta=46.5 \mathrm{ergs} / \mathrm{cm}^{2}
$$

is still untenable, because $\sigma_{l v} \cos \theta$ can never be greater than the surface tension of toluene, which is 27.9 at $25^{\circ} \mathrm{C}$. Mizushima attributed the above relation to Bartell and Merrill $^{2}$ without realizing that these authors have never used $\sigma_{l v} \cos \theta$ to evaluate the adhesion tension of systems like toluene-glass.

In the application of adhesion tension $\left(A \equiv \sigma_{s}-\sigma_{n}\right)$ it should be noted that $A$ depends not only on the nature of the liquid and the solid, but also on the structure of the solid surface. For instance, against the same liquid the (111) plane of $\mathrm{NaCl}$ would undoubtedly give different adhesion tension value than the $(100)$ plane. Even with amorphous substances such as charcoal different samples will of ten give different $A$ values against the same liquid. ${ }^{3}$ It is, therefore, erroneous to assume that when equal areas of two solids of the same chemical composition are compared, they will invariably show identical energy effects. In order to test his theory, Mizushima compared the $\Delta G$ value calculated from the adsorption data of Carver ${ }^{4}$ with the adhesion tension value of Bartell and Merrill and obtained excellent agreement. Carver's data, however, were obtained with Pyrex glass while the adhesion tension value cited $\left(46.5 \mathrm{ergs} / \mathrm{cm}^{2}\right)$ was for fused quartz. There is no reason to expect that two such different solids would show the same surface characteristics. Hence these data are not comparable. It is also to be noted that in the adsorption of vapors by plane surfaces at saturation pressure, the change in surface energy is not $a\left(\sigma_{s l}-\sigma_{s}\right)$ but $a\left(\sigma_{s l}+\sigma_{l_{v}}-\sigma_{s}\right)$, because a liquid surface has been created. This factor has not been considered by the author. Furthermore, it is a well-known fact that cleaning agents often roughen glass surfaces to such an extent that the effective surface area may be many times greater than the macroscopic geometric value. ${ }^{5}$ Since Carver has subjected his glass to quite drastic treatment, it is very probable that the true area is much greater than the value given in his paper. Hence, Mizushima's $\Delta G$ value $\left(44 \mathrm{ergs} / \mathrm{cm}^{2}\right.$ ) may be easily in error by many hundred percent.

From the above discussion the only conclusion which seems justified is that the close agreement of the two energy values obtained by Mizushima only serves to reveal the incorrectness of his theory.

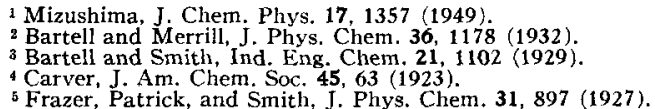

\section{The Stability of Gaseous Nitryl Chloride}

Richard A. OGG, Jr.* and M. KENT Wilson Mallinckrodt Chemical Laboratory, Harvard University, Cambridge, Massachusetts May 1, 1950

T $\mathrm{O}$ date there had been no study of thermodynamic properties of nitryl chloride, $\mathrm{ClNO}_{2}$. However, it appears to be a matter of common belief that nitryl chloride cannot be formed in significant amounts from $\mathrm{Cl}_{2}$ and $\mathrm{N}_{2} \mathrm{O}_{4}$, and that it does decompose into these substances. ${ }^{2}$ The inferences regarding equilibrium are obvious, and would enable estimation of a rough limit for the standard free energy of formation of $\mathrm{ClNO}_{2}$. In studies aimed at structure analysis we have observed the infra-red absorption spectrum of gaseous $\mathrm{ClNO}_{2}$, prepared both by ozonization ${ }^{1}$ of CINO and by the reaction of chlorosulfonic acid with anhydrous nitric acid. ${ }^{2}$ (The latter affords a greatly superior preparative method.) The spectrometer and cells were the same as described previously. ${ }^{3}$ In the spectral region between 2 and $16 \mu$ there are four strong characteristic bands, at approximately 1700,1340 , 1275 , and $795 \mathrm{~cm}^{-1}$ respectively. These allow ready detection and quantitative estimation of nitryl chloride in gaseous mixtures.

Immediately after preparation, mixtures of gaseous $\mathrm{Cl}_{2}$ and $\mathrm{N}_{2} \mathrm{O}_{4}$ (both at partial pressures of the order of $100 \mathrm{~mm} \mathrm{Hg}$ ) displayed only the bands of $\mathrm{N}_{2} \mathrm{O}_{4}$ and $\mathrm{NO}_{2}$. On standing at room temperature there was noted the gradual appearance of the above $\mathrm{ClNO}_{2}$ spectrum accompanied by those characteristic respectively of $\mathrm{N}_{2} \mathrm{O}_{5}{ }^{3}$ and CINO. (The latter has two moderately strong bands at approximately 1790 and $920 \mathrm{~cm}^{-1}$.) Concentrations of the various components became practically constant after some ten hours at room temperature. That these final concentrations correspond closely to chemical equilibrium was showr by variation of the initial concentration of $\mathrm{Cl}_{2}$ and $\mathrm{N}_{2} \mathrm{O}_{4}$.

It is apparent that equilibrium in the reaction

$$
\mathrm{Cl}_{2}+\mathrm{N}_{2} \mathrm{O}_{4} \rightleftharpoons 2 \mathrm{ClNO}_{2}
$$

is rather slowly attained, but that it corresponds to a much greater stability of $\mathrm{CINO}_{2}$ than had previously been supposed. Variation of temperature over a considerable range indicated that the formation of $\mathrm{ClNO}_{2}$ by the above reaction is an exothermic process. The reaction

\section{$\mathrm{N}_{2} \mathrm{O}_{5}+\mathrm{ClNO} \rightarrow \mathrm{N}_{2} \mathrm{O}_{4}+\mathrm{ClNO}_{2}$}

had previously been studied, using a different method, by $\mathrm{Mr}$. Ralph Weston at Stanford University (these studies will be reported elsewhere), and found to be extremely rapid. It is apparent that this equilibrium is also established in the present system, with comparable concentrations of CINO and $\mathrm{ClNO}_{2}$.

It was further found that the spectrum of $\mathrm{ClNO}_{2}$ appeared in mixtures of $\mathrm{O}_{2}$ and $\mathrm{ClNO}$, the rate increasing rapidly with addition of $\mathrm{N}_{2} \mathrm{O}_{4}$. The equilibrium

$$
2 \mathrm{ClNO}+\mathrm{O}_{2} \rightleftharpoons 2 \mathrm{ClNO}_{2}
$$

